\title{
Scholars GeoPortal:
}

\section{A New Platform for Geospatial Data Discovery, Exploration and Access in Ontario Universities by Elizabeth Hill and}

\author{
Leanne Trimble'
}

\begin{abstract}
The need to support and promote the use of geospatial data and available collections has grown at Ontario Universities in recent years. These data, along with numeric data collections, are used to enhance research and expand the skill set of students graduating from a broad array of disciplines. Providing access to these types of data collections has proven challenging, and access points available to large groups of people inside academia, in government and public domains have been made possible through online portal implementations. The defined need for a geospatial portal at Ontario Universities is outlined in the first part of this paper, followed by components of the Geospatial Portal Project vision and specific requirements and technical aspects of the project. How metadata is handled is also discussed, as is the implementation of the portal's web application. Additional project components include health data collections that are available to researchers and which could be used in conjunction with the portal. Finally, project governance and future growth beyond the Ontario user base are also discussed. ${ }^{2}$
\end{abstract}

Portal, including its staff of librarians, developers, and systems specialists who develop and support its services. Established Scholars Portal platforms include electronic journals, electronic books, and a data delivery system named ODESI (Ontario Data Documentation Extraction Service and Infrastructure; http://odesi.ca).

The international data which feeds into this type of social science research is produced by intergovernmental organisations (IGOs) such as the International Monetary Fund, the International Energy Agency, OECD, the United Nations and the World Bank. These organizations have a presence in every country in the world, the authority to create international standards and the technical and financial capacity to support the development of national statistical infrastructures. They have long produced high quality, regularly updated time series databanks for their own internal use which typically contain a huge range of macro-economic and social indicators aggregated to national or regional level and collectively cover virtually every country in the world. The academic research community needs access to these unique datasets in
Keywords: geospatial

data, data access

platforms, geospatial

metadata, software

development,

collaborative projects

\section{Introduction}

This paper describes a presentation given by Elizabeth Hill, Leanne Hindmarch (now Trimble), and Jennifer Marvin at the June 2011 IASSIST conference (Vancouver), entitled OCUL's Geospatial Portal Project: From Vision to Reality. This paper will elaborate on the progress of the project, which is an initiative of the Ontario Council of University Libraries (OCUL). OCUL is a consortium of all twentyone university libraries in the province of Ontario, and is involved in collective purchasing, storage, and delivery of library resources and services. The technical infrastructure to accomplish this is provided by OCUL's Scholars Portal program. Since 2002, Scholars Portal has hosted shared collections and has been involved in building, maintaining, and/or supporting a range of platforms for collection delivery to end users. ${ }^{3}$ OCUL member institutions all contribute funds toward the operation of Scholars order to contribute to and comment on policy responses to global issues. Furthermore, access to these data resources give students the opportunity to work with real world data.

\section{The need for a geospatial portal}

OCUL member libraries support the use of maps and geospatial data in many ways, including the licensing and management of geospatial data collections and software packages; distributing these geospatial data collections to users; and providing instruction on geospatial literacy and data use. OCUL Map and GIS Librarians recognized that there was a significant duplication of effort across institutions providing the first two of these services to their individual constituencies. Geospatial data collections were stored locally at each institution, resulting in challenges obtaining sufficient storage space given the vast size of many geospatial datasets. In addition, each institution had its own 
practices in place for distributing data to users, ranging from home grown online data delivery systems, to burning data onto DVD for each individual request.

The resources available to provide geospatial services varied widely from institution to institution, with many of the smaller OCUL libraries finding themselves challenged to support geospatial data given fewer staff resources and smaller budgets. Few institutions, large or small, had the resources or expertise to create and maintain a sophisticated, automated data delivery system. As a result, a significant amount of time was being spent on repetitive data management and distribution tasks, leaving staff fewer opportunities to devote time to work with faculty on the development of strategies aimed at improving students' spatial literacy and information skills

It was because of these challenges that OCUL embarked on a new project in 2008, to create a platform for the online delivery of geospatial data resources to the OCUL community. By leveraging the shared infrastructure and expertise already available at Scholars Portal, the geospatial portal project could reduce duplication of effort and improve access to geospatial data by offering a suite of tools that individual institutions would not have the capacity to support alone. Together, ODESI and the geospatial portal would facilitate the growth of Ontario's research capacity by making statistical and geospatial data more consistently available.

\section{Developing the vision}

In 2008, OCUL formed a working group to assess the state of geospatial library services across Ontario universities, specifically with respect to data collection management, including an audit of how geospatial data files were being used and delivered. The working group also familiarized themselves with geospatial data management in current, international context.

For example, the literature on Spatial Data Infrastructures (SDI) provided excellent information on best practices for geospatial data sharing and access. The concept of Spatial Data Infrastructure (SDI) is one which has been around for nearly two decades, and implies "a reliable, supporting environment, analogous to a road or telecommunications network, that, in this case, facilitates the access to geographically-related information using a minimum set of standard practices, protocols, and specifications" (Nebert, 2004, p.8). The idea of using established standards for the sharing of data and metadata proved to be important to this project.

The working group also investigated the role of geospatial portal applications, and examined a number of existing geospatial portals. Two important examples that existed when this research was being conducted included the US government's Geodata One-Stop (now known as geo.data.gov), and the Canadian GeoConnections Discovery Portal (http://geodiscover.cgdi.ca/). In Canada there are also various regional portals that were examined. In 2004, the Open Geospatial Consortium developed a guide to implementing geospatial portals as part of standards-based spatial data infrastructures (Rose, 2004). The guiding principle used in this document is the concept of serviceoriented architecture, in which software can communicate with content from disparate sources through a web services model.

It was also important for the working group to examine the topic from an educational perspective. At that time, most geospatial portal initiatives were affiliated with government, however, some international organizations had examined the impact on the educational community. The findings of an inventory of geospatial repositories conducted by EDINA at the University of Edinburgh by Stuart Macdonald, titled Data Visualizaton Tools: Part 2 - Spatial Data in a Web 2.0 Environment and Beyond, served as a guiding document for the working group. This report, published in September 2008, highlights a series of "Web 2.0" initiatives that were developed with the primary purpose of permitting users to visualize and manipulate data geospatially, in some cases in an open source environment. Macdonald points out that utilities such as these "empower the novice user by enabling the creation of spatial representations and visualisation with a minimal knowledge of the underlying technology" (p.6). As geospatial web computing becomes more advanced, more and more applications focus on the user experience; allowing users to visualize data, perform queries and analysis, create, annotate and share maps, and build a social experience around the use of geospatial data. This is sometimes referred to as an extension of the "Web 2.0" trend, or "Geo 2.0".

Macdonald's paper validated the urgent need for Ontario academic institutions to develop something of this nature. The proposed geospatial portal, a partner to the existing ODESI platform for statistical data delivery, would increase use of numeric and geospatial files by students at all levels, thus improving statistical and geospatial skills of students in Ontario. Since, as Macdonald states, "spatial data lends itself to visualisation", the tool would encourage novice users to increase their comfort level working with data by doing so in a visual way (p.17). In addition, the portal would provide new opportunities for libraries to engage with both students and faculty about the teaching \& learning of geospatial concepts. Finally, as web technologies continue to improve, it would be possible to offer sophisticated data manipulation and extraction tools for advanced users, meeting the needs of those constituents as well.

In 2008, OCUL held a "Geo-visioning Day," which brought together researchers, students, and librarians to synthesize the research about the current landscape for web GIS in teaching and research, and to assess interest, need, and support for a centralized geospatial file delivery service at Ontario universities. The Geo-visioning Day led to the fleshing out of the project's goals, which reflected the dual need of addressing unequal levels of service at Ontario university libraries and improving the use of limited library staff resources, as well as capitalizing on the opportunities of Geo 2.0 to develop a suite of tools accessible to both novice and advanced users. In particular, support for novice users was to be integrated throughout the final product. Finally, existing data collections were assessed and a need was identified for improved access to health-related data; this became another important aspect of the project.

Based on these decisions, a project scope was developed, and a successful application was made for support from the Government of Ontario through its OntarioBuys initiative. The project's official name is the Geospatial and Health Informatics Cyberinfrastructure Portal Project, however the portal itself has since been branded "Scholars GeoPortal".

\section{Project governance}

Scholars GeoPortal has a project governance structure, which oversees the project planning and implementation. The participating committees include an External Advisory Committee, a Project Management Group, and three working groups: 
- Technical, Standards, and Collections. This group's primary task has been to develop the functional requirements and provide ongoing feedback on development progress. In addition, a subcommittee developed a Metadata Best Practices Document based on the North American Profile of the ISO19115 metadata standard. The team also developed a model license for geospatial data, and established a priority list for the loading of geospatial data into Scholars GeoPortal. - Health Data Collections. Responsible for investigating health data collections for inclusion in Scholars GeoPortal or in ODESI (this is a joint committee between the data Odesi and map Scholars GeoPortal groups)

- Teaching \& Learning. Responsible for developing training and instructional tools of various kinds, and supporting Scholars Portal in the development of relevant Scholars GeoPortal features.

\section{Functional requirements for Scholars GeoPortal}

Based on the project goals as developed from the Geo-Visioning Day exercise, and with additional feedback from the project working groups, a comprehensive list of needed functionality was drafted, which was grouped into the following major categories:

\section{Standards-compliant metadata}

Like in other realms of the library world, standardized metadata is vital to facilitate search and discovery. There are several metadata standards that are commonly used for describing geospatial data. The most established standard is the Content Standard for Digital Geospatial Metadata (CSDGM), created and maintained by the Federal Geographic Data Committee (FGDC) and commonly referred to as simply the FGDC standard (1998). However, this metadata standard is gradually being superseded by a newer ISO standard known as ISO19115: 2003 - Geospatial Information - Metadata (International Organization for Standardization, 2003). This standard offers a detailed and comprehensive set of metadata elements for describing geospatial datasets, and offers the added benefit of allowing for the creation of "profiles" for specialized user groups or jurisdictions. The North American Profile (NAP) was created by the American INCITS Technical Committee L1, Geographic Information Systems and the Canadian General Standards Board Committee on Geomatics (CGSB-CoG), with feedback from the user communities in both Canada and the United States, and was released in 2009.

One of the project working groups, the Metadata Standards Working Group (which later merged into the Technical, Standards, and Collections Working Group described above), conducted a thorough review of the relevant metadata standards, and recommended that the project adopt the (at the time) brand- new North American Profile of ISO 19115, which is also gradually being adopted by provincial and federal government entities in Canada. Therefore, a metadata editor was needed which met the following criteria:

- Compliant with the NAP standard and allow for the export of NAP-compliant xml.

- Supports the use of multiple controlled vocabularies (selected by the Metadata Standards Working Group) for describing topics and places.

- Accessible to multiple metadata creators/editors who might be located at different OCUL libraries.

- Able to interface seamlessly with the Scholars GeoPortal web application.

The project's Metadata Standards Working Group developed a comprehensive Best Practices Guide, which describes how the NAP metadata standard is being used for the Scholars GeoPortal. ${ }^{4}$

\section{Online mapping tool}

The online mapping tool is the main Scholars GeoPortal component that users interact with (available at http://geo.scholarsportal.info). This tool provides OCUL students, staff, and faculty with access to the range of consortially-licensed data collections that are available to them through their libraries. For many OCUL universities, this is the first time that these data collections are available for online download, both onand off-campus.

In planning for the technical implementation, it was decided that the online mapping tool needed to incorporate the following fundamental features:

- Offer a range of options for searching the metadata collection and displaying search results.

- Allow the user to display and/or download a complete NAP metadata record if desired.

- Allow the user to preview each dataset in a dynamic fashion within the mapping tool.

- Allow for the validation of users and the presentation of end-user terms of use agreements.

- Allow the user to query features and/or view the attribute tables associated with each dataset, to assist in assessing whether the dataset meets their research needs.

- Allow the user to select an area of interest and download their datasets, which would be clipped to the area of interest ("clip \& ship"). Downloads needed to be available in a range of file formats and projections. Additionally, allow the user to download full datasets when they do not need to clip an area of interest.

\section{Teaching \& learning support}

In addition to the core data access functionality described above, it was important that additional features be incorporated which would support the teaching of spatial literacy and geospatial data use skills. These features would provide added value to faculty who wish to incorporate Scholars GeoPortal into their lectures, assignments, or other course work, and to students who wish to create simple maps as part of their academic work, without using complex desktop GIS software.

- Integrated help tools. Scholars GeoPortal provides contextsensitive tips and information to assist users in becoming familiar with the terminology used and tools available (for example, what is a projection and how does one decide which projection they wish to use?). This is important for users who may not have GIS expertise but still wish to make good decisions when creating a simple online map.

- Printing and Exporting. This feature allows users to generate maps with title, legend, and data source list, and output the map to a PDF or image file (e.g. for inclusion in an assignment).

- User accounts. This feature allows users to save maps, searches, and user-defined area-of-interest polygons into a personal user account in order to access them again at a later date.

- Permalinking. This feature generates a permalink that replicates the user's map state, opening Scholars GeoPortal and loading their selected layers, zoom and extent information. For example, a professor could use this to share a map or dataset list with their students.

- Map annotation. This feature allows users to enhance their online map by adding their own points, shapes, and lines onto the map and associate notes or images with these markers.

\section{Scholars GeoPortal components}

A request for proposals (RFP) was issued by OCUL in 2009 that resulted in the selection of the ArcGIS suite of software from ESRI Inc. to serve 
as the platform for serving geospatial data and creating a web portal application. ESRI technology is used in conjunction with other software already available at Scholars Portal (such as MarkLogic xml database), and is supported by a server and storage infrastructure as described in Figure 1.

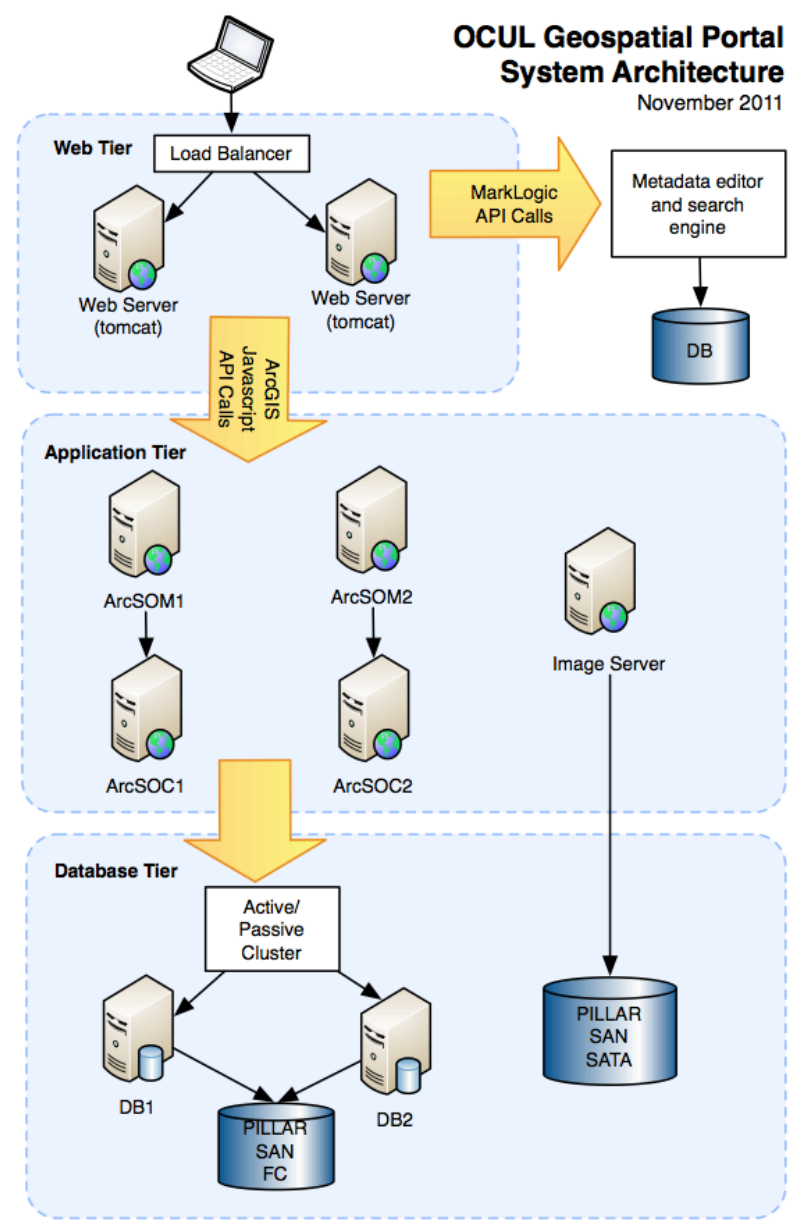

Figure 1. Scholars GeoPortal System Architecture Diagram

In order to accomplish the functional requirement described above, Scholars GeoPortal consists of the following main components.

\section{Metadata database and editor}

The metadata collection is housed in a MarkLogic database. MarkLogic is a powerful database management system which is excellent for storing xml data. Scholars Portal uses MarkLogic to store xml metadata for many of its other services and its staff has considerable expertise with the software. For Scholars GeoPortal, metadata records are loaded into the database and then edited using a custom-built metadata editor, which communicates with the database using the XQuery query language. The Scholars GeoPortal web application itself also queries the database directly using an API.

The metadata editor allows OCUL librarians to load and edit NAPcompliant metadata records in an easy-to-use interface, as well as export the completed metadata record in $\mathrm{xml}$ format. Wherever possible, metadata records are obtained from data providers, converted to the NAP/ISO 19115 standard, and loaded into the database, where additional information is then added (such as controlled theme and place keywords). ${ }^{5}$ Currently, metadata is being edited by Scholars Portal staff, but plans are in place to build an entitlements management component to the editor, that will allow metadata editors from OCUL libraries to login in order to edit and manage metadata records, permitting distributed metadata management. (see Figure 2.)

\section{Spatial database}

The vector data included in Scholars GeoPortal are housed in an ESRI SDE geodatabase. Raster data are stored on a separate server and are referenced from ESRI mosaic datasets, which are stored within a file geodatabase.

\section{Web map services}

ArcGIS Server allows Scholars Portal to publish web mapping services which permit users to interact with OCUL dataset collections in an online environment. The Scholars GeoPortal web application includes ESRI map services and image services; ArcGIS Server also supports the publishing of OGC services including WMS, WFS, and WCS. Scholars Portal serves the OCUL licensed data collections through map and image services, which are designed and published in-house. These are then invoked by Scholars GeoPortal when a user clicks an "Add" button in the search results display, and are added to the map viewer over a base map. (see Figure 3: )

\section{Web application}

When making plans to develop an online mapping tool that would communicate with Scholars Portal's ArcGIS Server data and services, there were a number of ESRI application developer frameworks (ADFs) and APIs to select from. Around this time, ESRI announced that the Web ADFs for . Net and Java were to be deprecated in the near future, and that support was moving entirely to the three REST APIs, for Javascript, Flex, and Silverlight. Since applications built using either Flex or Silverlight require the end user to download and install a browser plug-in (which is not possible on many locked-down campus computers), it was decided to use the Javascript API.

The ArcGIS Javascript API allowed Scholars Portal to build a web application with an embedded map view, which can display a range of base maps hosted by ESRI, as well as those created by our own web mapping services. Users can search the metadata repository and view detailed information about the datasets contained in Scholars GeoPortal (see Figure 4). They can then "add" the data to the map by clicking a button that invokes the Scholars Portal-hosted web mapping service containing that dataset. Once data has been displayed on the map, there are a number of ways the user can work with the data. From the "Map" tab, they have the option to toggle layers on and off, re-order layers, and change their transparency. In addition, clicking on the map provides attribute information about the features at the location clicked on (see Figure 5). In addition, the application offers "clip \& ship" functionality, whereby the user can select layers representative of an area of interest, and an output format/projection and the system will generate a zipped file for download (see Figure 6).

For users without desktop GIS software expertise, it is also possible to create, export, save and share an online map from Scholars GeoPortal. The "Share" feature generates a permalink to the map created by the user, while the "Export" feature provides the option to print or save the map in a range of formats. The exported map includes a user-defined title, important map elements like a legend and scale bar, and a data credits (see Figure 7). A future release will include full citations to each dataset on the map, encouraging students to include data citations in their assignments. Scholars GeoPortal also offers map annotation 


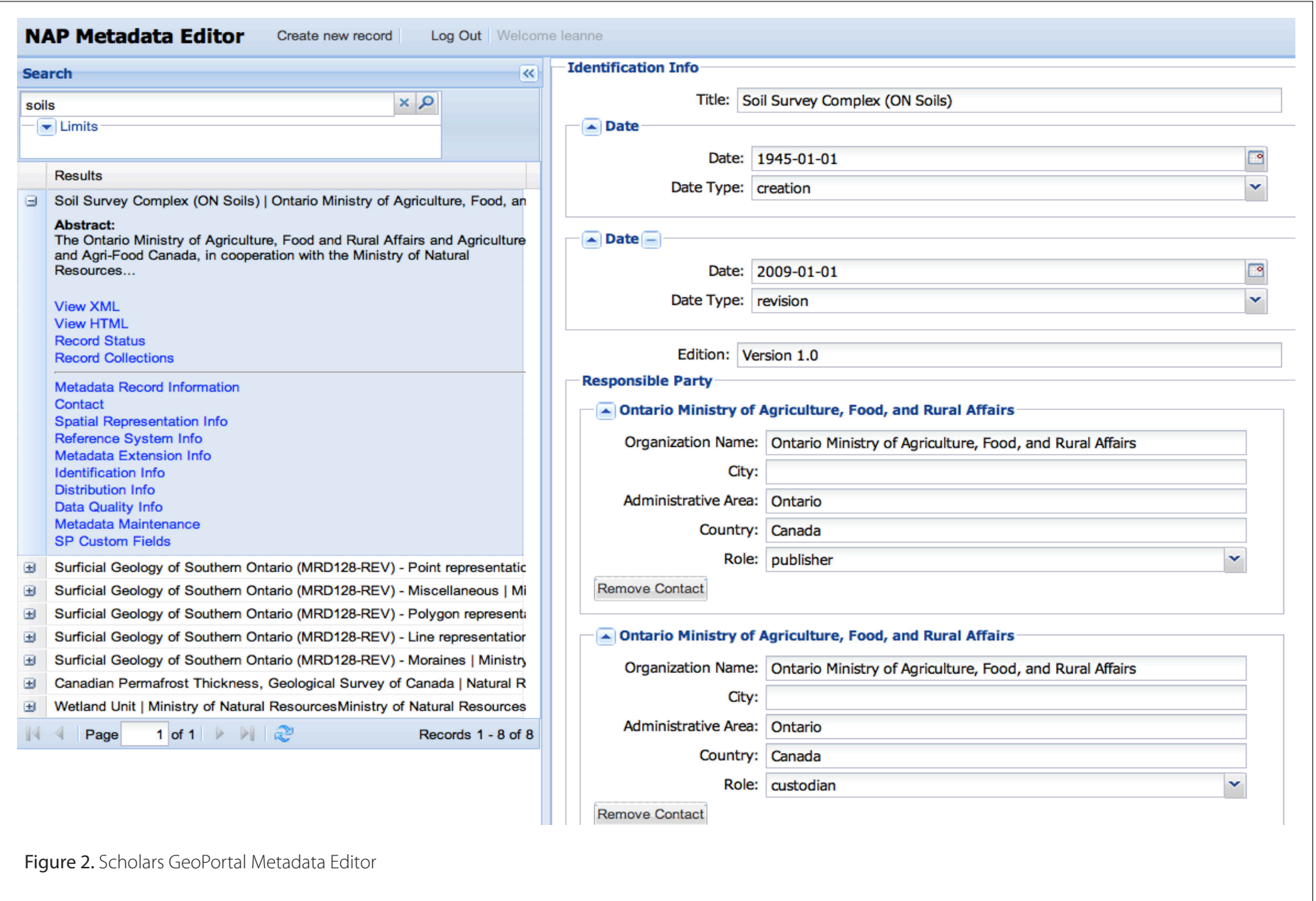

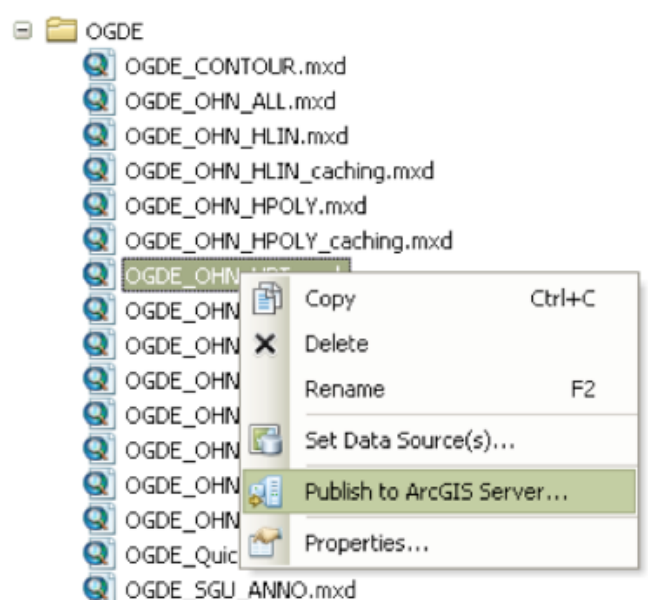

Figure 3: Map documents are created in ArcMap and then published to ArcGIS Server using ArcCatalog. The web application makes requests to ArcGIS Server in order to display the service on the map.

features, allowing users to draw their own markers on the map and label them. These can be saved, along with the map, to an individual user account for future access (see Figure 8).

Help tips are sprinkled throughout the portal to answer questions that users may have about the options available and terminology used (see Figure 9). In addition, the Teaching \& Learning Working Group have used Springshare's LibGuides to create a Help Guide which offers stepby-step instructions for the different tasks which can be performed in Scholars GeoPortal (see Figure 10).

\section{Other project initiatives}

\section{Additional teaching \& learning support}

While teaching and learning support is a key implementation consideration in the design of Scholars GeoPortal, there is quite a bit more that can be done to encourage spatial literacy and use of GIS in a wide range of academic disciplines. To that end, the project's Teaching and Learning Working Group is involved in creating a variety of online resources to build upon the context-sensitive help provided within Scholars GeoPortal. The first of these initiatives is the creation of an online User Guide for use with Scholars GeoPortal (http://guides. scholarsportal.info/GeoPortal). This will be expanded to include screencast tutorials, videos, and other learning resources.

Scholars GeoPortal is intended to serve the entire range of users, from novice to expert. The integrated teaching and learning modules will enable novice users, particularly those from non-traditional GIS disciplines, to accomplish tasks with ease, developing confidence and expertise with GIS tools. These resources will also be important teaching tools, available for use within course offerings and by librarians providing reference support.

\section{Health data collections}

The core collections available to OCUL students, staff and faculty include licensed collections from both government and commercial data producers. However, as mentioned above, one of the objectives of the Scholars GeoPortal project was to explore ways to increase access to health data collections. This has been an area of weakness within OCUL's licensed collections because many health data stewards are not currently mandated to provide access to anonymized or public use files, and there are many roadblocks in place for researchers, particularly students, wanting to obtain access to health data. 


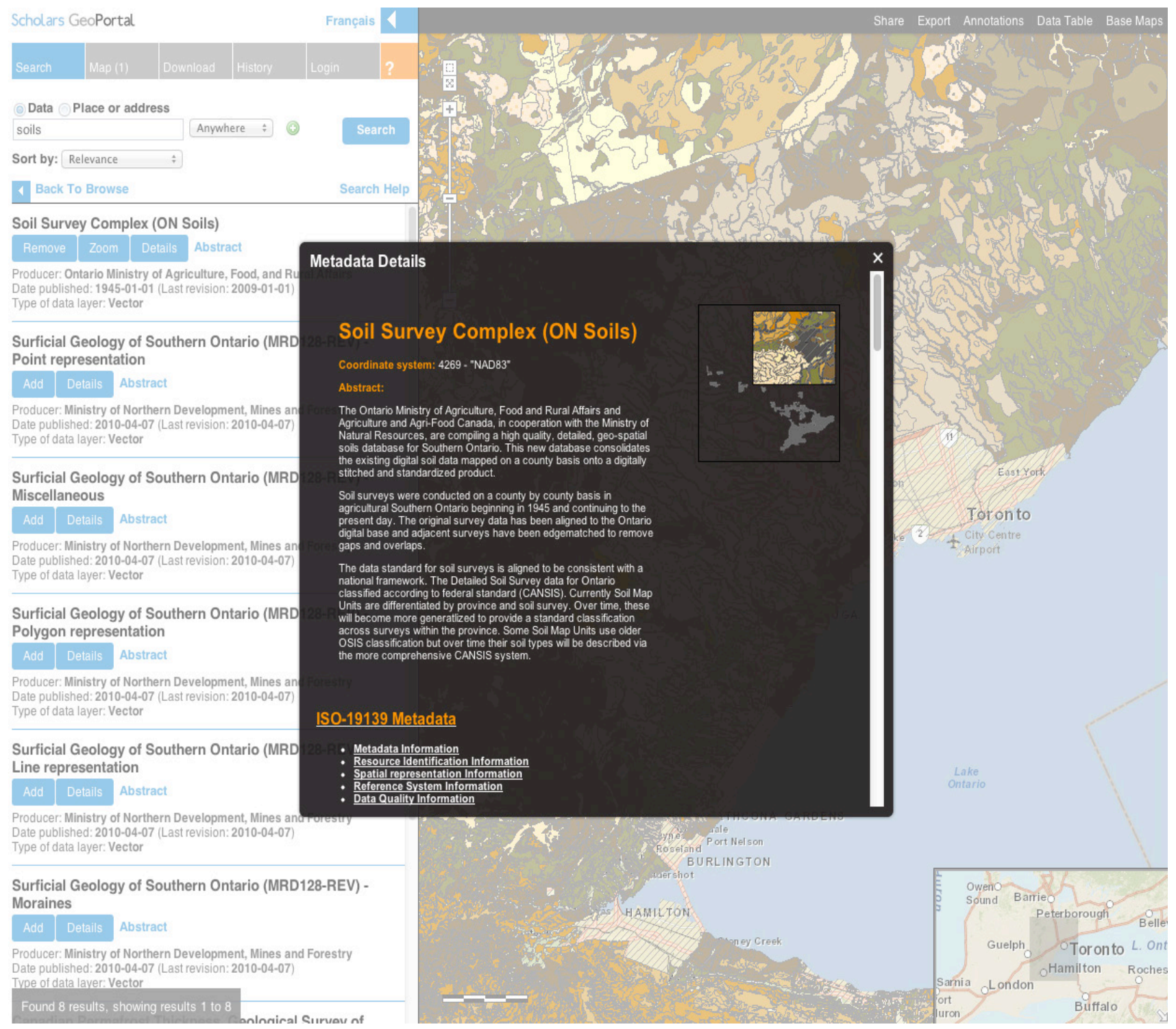

Figure 4: Scholars GeoPortal - metadata detail view.

In parallel to the technical implementation part of the project, a Health Data Collections Working Group was formed. This group has undertaken a range of initiatives towards the goal of improved health data access, including organizing a Health Data Summit in March 2011. This day-long event brought together researchers, librarians, data providers, policy makers, and legal experts to contribute to the discussion on access to and use of health data. The Summit was a learning experience for OCUL, helping the group become more knowledgeable about the range of issues affecting the availability of health information, including privacy and confidentiality, and the challenges associated with the resource-intensive process of anonymizing data so that individuals cannot be re-identified. Health data collections will be a long-term initiative for OCUL, and we will continue to communicate with data producing organizations to identify ways to overcome these barriers and increase our health data holdings for academic use..

\section{Model licensing}

Members of the project's Collections Working Group (which later merged into the Technical, Standards, and Collections Working Group), developed a model data license agreement, which is intended to serve as a model for how agreements for licensing geospatial data collections should be structured (the model license is available on the OCUL website at http://www.ocul.on.ca/node/114). While it is recognized that data providers/licensees develop their own license templates and requirements, it is hoped that the OCUL model license can help inform discussions and negotiations.

\section{Assessment}

A number of assessment initiatives have been undertaken as part of the Scholars GeoPortal project. One of these asks each OCUL GIS/ Map Library to track statistics about the usage of their services and the time spent on various types of activities (, systems support, data and metadata management, data reference, instruction, etc.). As Scholars GeoPortal usage grows, these data will be useful in assessing what impact Scholars GeoPortal has on the nature of geospatial data library services in Ontario university libraries.

In addition, OCUL has conducted a survey of researchers, which asked them about their use of geospatial data for research and teaching, their sources for acquiring data, their knowledge of geospatial library resources, and what features they would most like Scholars GeoPortal to offer. The results of this survey are currently being analyzed. OCUL's goal is to conduct a second survey once Scholars GeoPortal has been in use for some time, to begin to assess 


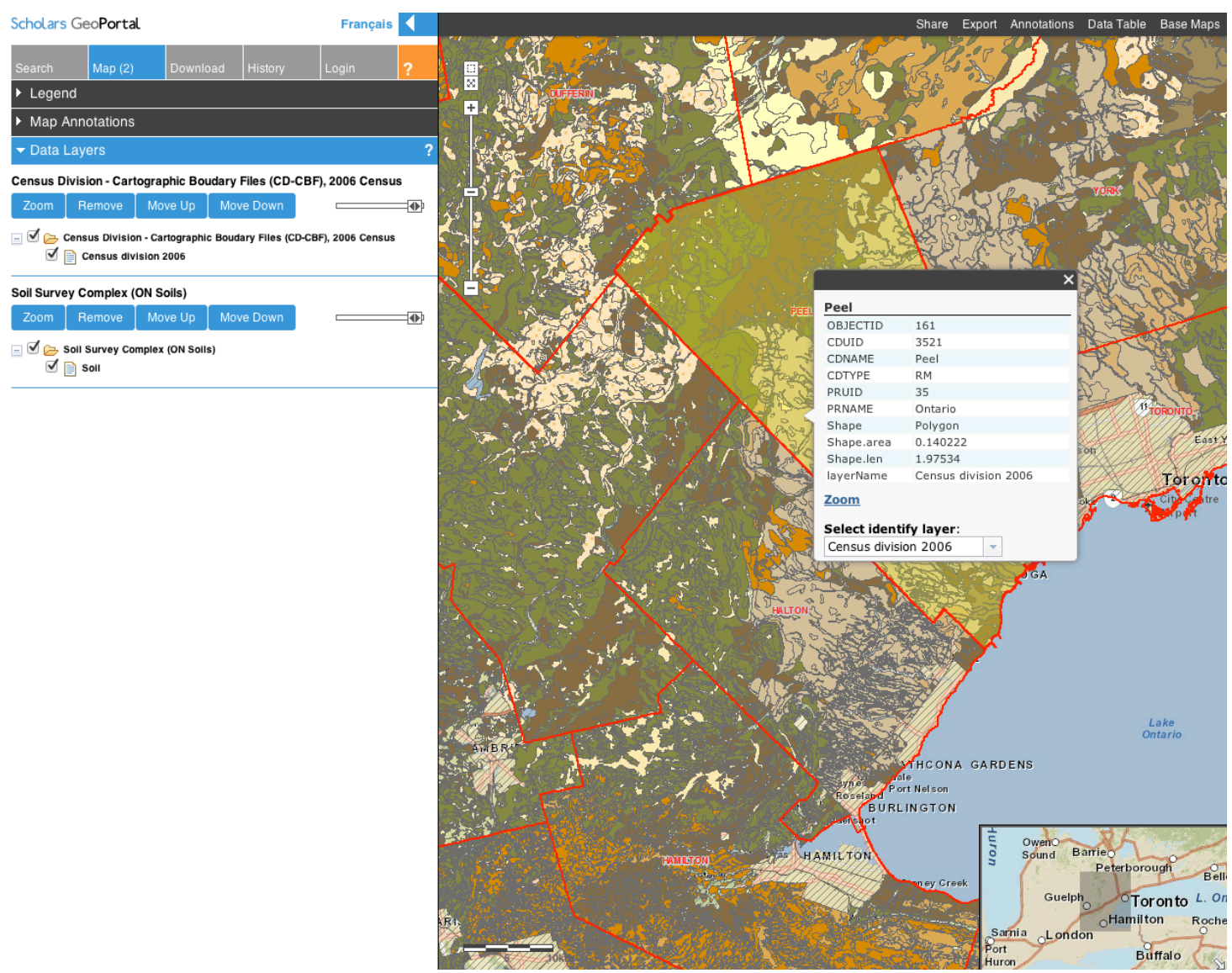

Figure 5: Scholars GeoPortal - map with several layers added. Clicking on the map provides information about the feature selected (from the attribute table).

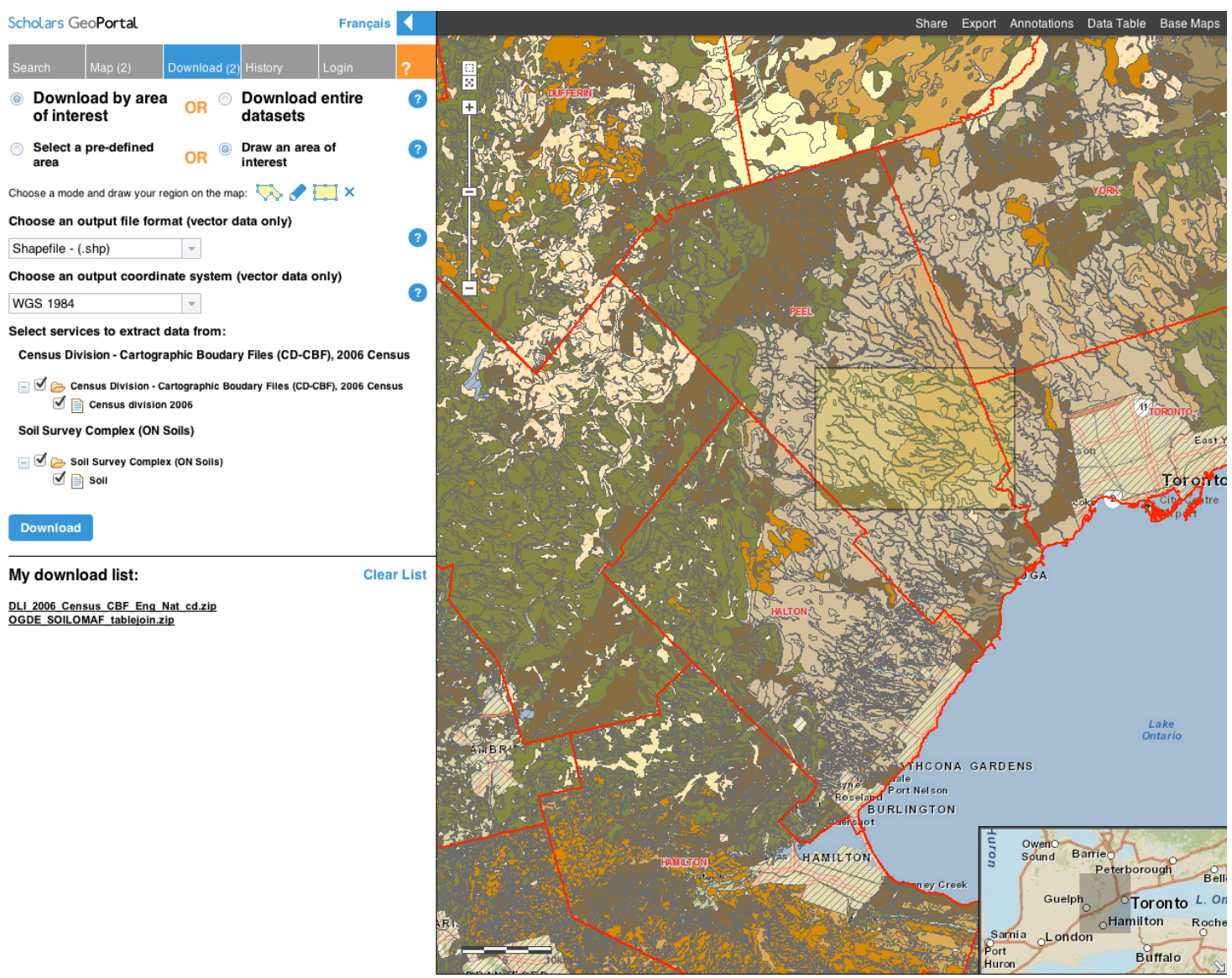

Figure 6: Scholars GeoPortal - download options and list of files ready to be downloaded. 
$\square$ Census division

$\square$ Loamy Sand

$\square$ Gravelly Sandy Loam

$\square$ Gravelly Sand

Sand

Sandy Loam

[. Coarse Sandy Loam

" Loamy Coarse Sand

$\square$ Fine Sand

$\square$ Fine Sandy Loam

$\square$ Loamy Fine Sand

- Loamy Very Fine Sand

[.] Very Fine Sandy Loam

Silt Loam

Silty Clay

Silty Clay Loam

$\square$ Clay

$\square$ Clay Loam

$\square$ Gravelly Loam

$\square$ Gravel

$\square$ Organic

Y, Non-Soil/Man-Made Features

\section{Soils of Peel County}



Figure 7: Scholars GeoPortal - exported map.

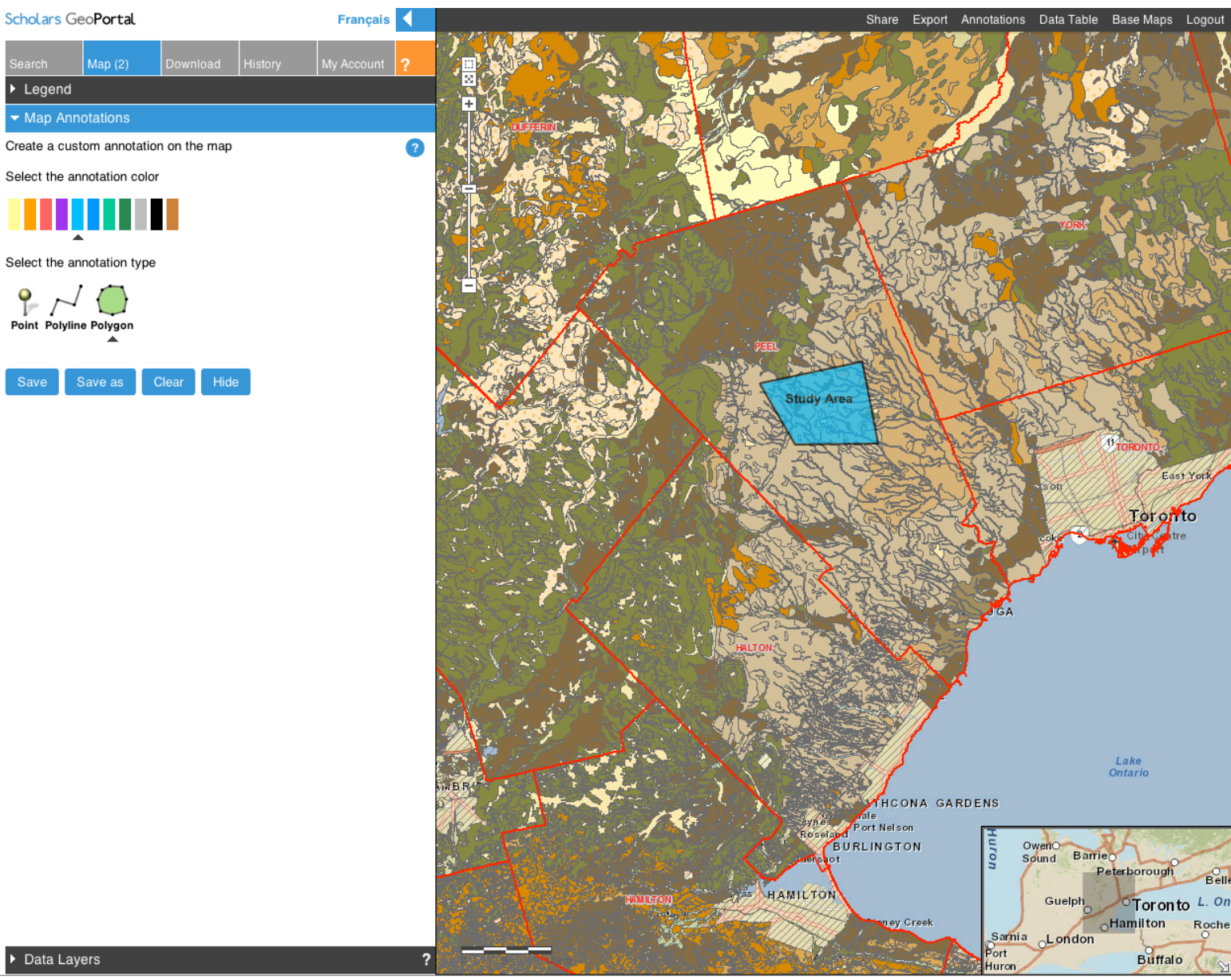

Figure 8: Scholars GeoPortal - map annotations and map saving options 


\section{Base Maps (Click here to Remove)}

A map on which GIS data layers are placed onto or registered to. Typically, base maps contain reference information such as place names, street names, landmarks and/or political boundaries.
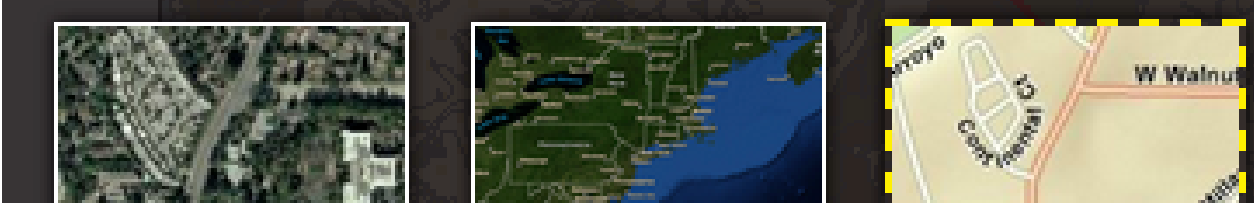

Figure 9: Scholars GeoPortal - example "help tip" - clicking on the question mark causes a small definition to appear.

whether access to the tool has had an impact on research and teaching using geospatial data.

Finally, OCUL conducted a usability study with student, faculty, and librarian participants, to identify issues with specific aspects of the Scholars GeoPortal web application. The results of this study will inform future development of the user interface.

\section{Benefits \& challenges of consortial projects}

This project has been collaborative from start to finish. Inevitably, there are challenges to such an approach. As rewarding as the work is, all professionals who have served on committees know that tasks can be more difficult to coordinate in a timely fashion when many individuals are involved, particularly when, as in the case of OCUL, they are distributed over a very large geographic area. While there were occasional opportunities to meet as a group, most of the decisionmaking for this project was done by conference call. Because of the number of parties involved (project administrators, technical staff, librarians, funding agencies, software vendors, etc.), decision-making was at times slower than anticipated, and staying on our timeline was a continual challenge, but deadlines were indeed still met.

Another challenge of the project was how new this area was to all participants involved. While there was considerable programming and systems expertise at Scholars Portal, and significant GIS expertise within the OCUL libraries, no one involved had participated in a largescale web GIS development project before. There was a learning curve in a number of areas, including discovering how to communicate effectively between stakeholders with differing areas of expertise.

Despite these challenges, it is truly the collaborative nature of the Scholars GeoPortal project that enabled its success. Without working together within the OCUL framework, the consortial data licenses that enabled this project to happen would never have existed in the first place. In addition, the centralized expertise and infrastructure at Scholars Portal could only be supported by working collaboratively.

\section{Moving forward}

On launch (March 1, 2012), Scholars GeoPortal was a robust data access tool that fills a distinct gap in Ontario library services. There's still much more to be done, however. In addition to the ongoing initiatives described above, OCUL has an interest in exploring the following areas:

\section{Expanding the tools}

The Scholars Portal team will continue to work on developing all of the features described in the functional requirements list, as well as embarking on new projects that further enhance the tools offered by the GeoPortal. One area of interest is to find better ways to link the geospatial and statistical data available through both ODESI and Scholars GeoPortal - for example, developing data visualization tools that allow users to select census or other data variables, in order to map them to a chosen administrative or statistical boundary level.

\section{Expanding the collections}

In addition to supporting the core collections described above, OCUL is interested in exploring which other data collections should also be included within Scholars GeoPortal. The project's Technical, Standards, and Collections Working Group is embarking on developing a collections policy that will help prioritize the possible initiatives, and this will be a topic for discussion as the initial development project comes to a close

One initiative under consideration is to develop a model for the loading of local data collections (which are licensed by only one or a few OCUL libraries). Scholars GeoPortal is able to manage entitlements so that only the appropriate users can gain access to the data, and license agreement terms are respected. For some OCUL institutions this would mean that Scholars GeoPortal can become a "one-stop-shop" whereby they do not need to maintain a local system. Another area to explore is how we might provide discovery tools for the range of open geospatial data collections now available.

\section{Conclusions}

OCUL's Scholars GeoPortal is poised to become an important tool supporting the use of geospatial data within OCUL universities. It meets a range of needs, both supporting OCUL Data, Map and GIS libraries by centralizing the management and distribution of consortially licensed data collections, as well as offering online search, preview, and download tools for students, staff, and faculty across the province. The project would not have been possible without many hours of hard work contributed by OCUL Librarians, the Scholars Portal Development Team, and the community members who participated on the External Advisory Committee.

While Scholars GeoPortal remains a work in progress, it has immense potential to support future development of new tools, and expansion of data collections. It will be exciting to see how Scholars GeoPortal grows.

\section{References}

Canadian General Standards Board. (2009). North American Profile of ISO 19115:2003 - Geographic information - metadata (NAP metadata), CAN/CGSB-171.100-2009. Gatineau, Quebec: Author. 
Federal Geographic Data Committee. (1998). Content standard for digital geospatial metadata, FGDC-STD-001-1998. Washington, D.C.: Author.

International Organization for Standardization. (2003). Geographic information - metadata, ISO 19115:2003. Geneva, Switzerland: Author.

Macdonald, S. (2008). Data visualisation tools: Part 2 - spatial data in a web 2.0 environment and beyond. JISC. Retrieved from http://www. disc-uk.org/docs/spatial_data_mashup_V2.pdf

Nebert, D.D. (Ed.). (2004). Developing spatial data infrastructures: The SDI cookbook. Global Spatial Data Infrastructure. Retrieved from http:// www.gsdi.org/docs2004/Cookbook/cookbookV2.0.pdf

Rose, L.C. (Ed.). (2004). Geospatial portal reference architecture: A community guide to implementing standards-based geospatial portals. OpenGIS Discussion Paper OGC 04-039 (draft). Retrieved from http:// portal.opengeospatial.org/files/?artifact_id=6669

\section{Notes}

1. Contact: Elizabeth Hill, Data Librarian, Map and Data Centre, University of Western Ontario, London, Ontario, N6A 5C2. Email: ethill@uwo.ca; Leanne Trimble (formerly Hindmarch), Map and Data Librarian, Scholars Portal, Toronto, Ontario, M5S 1A5. Email: leanne. trimble@utoronto.ca.

2. This paper is an updated version of one presented at the IASSIST 2011 conference at University of British Columbia in the session "Power of Partnerships in Data Creation and Sharing".

3. For more information on Scholars Portal, visit http://scholarsportal. info

4. The Scholars GeoPortal Metadata Best Practices Guide is available on the Scholars GeoPortal wiki at http://spotdocs.scholarsportal.info/ display/geospatial/OCUL+Geospatial+Portal (under "Documents")

5. The Metadata Standards Working Group recommended two thematic keyword thesauri: the Government of Canada Core Subject Thesaurus (from Library and Archives Canada) and the LIO-MNR Thesaurus (from the Ontario Ministry of Natural Resources). In addition, they recommended two place name vocabularies: CEONET (used in the GeoConnections Discovery Portal) and the Global Change Master Directory's Location keywords. To date, all but the CEONET thesaurus have been implemented within the metadata editor. In addition, French-language versions will be implemented where available. 